Check for updates

Cite this: RSC Adv., 2019, 9, 9106

Received 21st December 2018 Accepted 26th February 2019

DOI: $10.1039 / \mathrm{c} 8 \mathrm{ra10453k}$

rsc.li/rsc-advances

\section{Rubidium ion Capture with a phosphotungstic acid-functionalized finger-citron-residue-based carbon $\uparrow$}

\begin{abstract}
Qing Liu, ${ }^{a}$ Guihua Zhao, ${ }^{a}$ Yifang Dai, ${ }^{\mathrm{b}} \mathrm{Na} \mathrm{Ma}{ }^{\mathrm{c}}$ and Wei Dai (D) *a
To solve the contradiction of diffusion and selectivity, we reported a novel finger-citron-residue-based mesoporous carbon (FMC) as a support to prepare a novel adsorbent PTA@FMC (PTA represents phosphotungstic acid) for rubidium ion capture. This new adsorbent was characterized by $\mathrm{X}$-ray diffraction, thermogravimetric analysis, scanning electron microscopy, Fourier transform infrared spectroscopy, and $\mathrm{N}_{2}$ adsorption, and the results showed that the PTA was immobilized in the FMC structure. Based on the results of batch tests, we demonstrated that PTA@FMC is the most distinctive adsorbent with a superior uptake capacity compared with some of those previously reported in the literatures. The adsorption tests in the presence of interfering ions $\left(\mathrm{Na}^{+}, \mathrm{K}^{+}\right.$and $\left.\mathrm{Cs}^{+}\right)$showed that the more the added amount of the different types of interfering ions, the more severe is the degree by which the adsorption of $\mathrm{Rb}^{+}$is weakened. In addition, the $\mathrm{Rb}^{+}$sorption selectivity was moderately influenced by the co-ion effect in the presence of any ions $\left(\mathrm{K}^{+}, \mathrm{Na}^{+}\right.$and $\left.\mathrm{Cs}^{+}\right)$due to PTA doping. In a word, due to its relatively facile preparation process and good uptake capacity, PTA@FMC might be a promising adsorption material for $\mathrm{Rb}^{+}$.
\end{abstract}

\section{Introduction}

Rubidium, a typical rare metal, has various applications in the field of photocells, thermoelectric generators, alkali batteries, biological engineering, and medical industries. ${ }^{1-3}$ In the recent few decades, due to the increasing demand for rubidium from industries, the price of the rubidium metal has been rocketing in comparison to those of other alkali metals. ${ }^{3}$ Although, the total content of rubidium ions in brine lakes is relatively high, the concentration of rubidium ions in those lakes is in trace amounts. ${ }^{4}$ Consequently, the separation, condensation and purification of rubidium ions are regarded as hot issues pertinent to scientific research fields.

In terms of the methods employed in the capture of rubidium ions, extraction, use of ion exchangers and adsorption are the most frequently used..$^{5-8}$ Among these, adsorption is considered as a potential method because it has the advantages of strong operability, as it can be carried out in ambient temperature and atmosphere by a simple process, and

${ }^{a}$ College of Chemistry and Life Science, Zhejiang Normal University, Jinhua 321004, Zhejiang Province, PR China. E-mail: daiwei@zjnu.edu.cn; Fax: +86-579-82282325; Tel: $+86-579-82282269$

${ }^{b}$ Class 14 of First Grade, Jinhua No.1 High School, Jinhua 321004, Zhejiang Province, PR China

${ }^{c}$ College of Geography and Environmental Sciences, Zhejiang Normal University, Jinhua 321004, Zhejiang Province, PR China

$\dagger$ Electronic supplementary information (ESI) available. See DOI: $10.1039 / \mathrm{c} 8 \mathrm{ra} 10453 \mathrm{k}$ reproducibility. ${ }^{7}$ At present, because of their adaptability to the size of rubidium ions and their relatively high specific surface area, the microporous adsorbent materials have wide applications in the field of rubidium ion adsorption. However, the ability of ordinary microporous materials to adsorb rubidium ions is restricted because of the limitations of the simple adsorption process. The adsorption of rubidium ions onto the adsorbents is controlled by the combination of physical adsorption and chemical adsorption. Physical adsorption has a poor adsorption selectivity for ions with rather limited adsorption capacity, while the chemical adsorption process is selective. Hence, amplifying the adsorption advantages of the chemical adsorption process to enhance the adsorption selectivity and thus increase the adsorption capacity of rubidium ions can be a meaningful research task. To be more specific, an effective way to realize this enhancement is to modify the adsorbent materials by introducing the functional groups that have specific affinity towards rubidium ions onto the original adsorbents. Studies in this attempt have been proved to be successful. ${ }^{3-21}$

Heteropoly acids are certain substances that have adsorption affinities with heavy metal ions. ${ }^{10}$ The introduction of a heteropoly acid on the adsorbent surface is thought to effectively enhance the chemical adsorption interactions of rubidium ions. One of the most representative MOF materials is HKUST-1 (also named as $\mathrm{Cu}-\mathrm{BTC}$ ), a particular type of MOF containing $\mathrm{Cu}$ (II)-paddle wheel-type nodes and 1,3,5-benzenetricarboxylate struts. In our previous study, ${ }^{3}$ a modified microporous 
adsorbent, PMA@HKUST-1, which has distinguishing adsorption properties for rubidium ions, was successfully developed by loading molybdophosphoric acid onto the microporous adsorbent HKUST-1. The effect of PMA@HKUST-1 on the adsorption of rubidium ions was gratifying. The use of PMA@HKUST-1 increased the adsorption amount of rubidium ions onto the adsorbents by approximately $28.5 \% .^{3}$ Even then the PMA@HKUST-1 was imperfect. The microporous structure of HKUST-1 was seriously damaged after the introduction of phosphomolybdic acid. In addition, the paradox of the relatively large molecular diameter of PMA and the finite pore size of HKUST-1 rendered the introduction of heteropoly acids a defective practice. The pores of the microporous adsorbents, after the introduction of the heteropoly acid, were blocked, the pore volume of the adsorbents reduced, and the diffusion efficiency of rubidium ions decreased, negatively disturbing the adsorption process. In the face of this undesirability, we came up with the idea of replacing the microporous material with a mesoporous material to enlarge the pore volume, which would be favorable for loading the heteropoly acid and the diffusion of adsorbates.

Supposedly, the pore size characteristics of the mesoporous materials facilitate the loading of heteropoly acid molecules in their pore structure without blocking the porous pathway, which is conducive to enhance the chemical adsorption capacity of rubidium ions. Theoretically, mesoporous materials with high specific area, uniform porous structures and good thermostability are promising support. ${ }^{9}$ Though few studies have been conducted on the application of mesoporous materials as in the adsorption of rubidium ions, the outcomes drawn from those studies are valuable. In H. Aghayan's study, ${ }^{22}$ substituted molybdophosphoric acid was loaded onto SBA-15 with various structural morphologies; the as-prepared samples showed a high adsorption ability towards thorium ions and the morphology of SBA-15 was decisively significant in guaranteeing an auspicious adsorption process. This study substantiated the validity of adopting a mesoporous material as the support, onto which heteropoly acids can be introduced. Phosphotungstic acid (PTA), a member of the group of heteropoly acids, has similarity in chemical properties with those of phosphomolybdic acid (PMA). ${ }^{23}$ In effect, in our previous work trials, ${ }^{12}$ a finger-citron-residue-based mesoporous carbon (FMC) was synthesized by filling the pores of a siliceous SBA-15 hard template with finger citron residues as the carbon precursors. Herein, we present a study on the rubidium ion capture with a new type of composite material PTA@FMC, including batch equilibrium experiments and adsorption mechanisms.

\section{Materials and methods}

\subsection{Chemicals and reagents}

Hydrochloric acid ( $\mathrm{HCl}, \geq 99 \%$ ), phosphotungstic acid hydrate $\left(\mathrm{H}_{3} \mathrm{O}_{40} \mathrm{PW}_{12} \cdot x \mathrm{H}_{2} \mathrm{O}, \geq 99.5 \%\right)$, and ethanol $\left(\mathrm{C}_{2} \mathrm{H}_{6} \mathrm{O}, 99.7 \%\right)$ were purchased from Sinopharm Chemical Reagent Co. Ltd. All the chemicals used in this study were of analytical grade and used without further purification.

\subsection{Preparation of PTA@FMC}

The FMC was facilely synthesized by a similar procedure to that in our reported work. ${ }^{24}$ The three samples in which different contents of PTA were loaded onto the FMC were prepared as follows: in each container, $1 \mathrm{~g}$ of FMC was weighed and equal volumes of PTA of $0.05 \mathrm{M}, 0.075 \mathrm{M}$ and $0.1 \mathrm{M}$ were added. The mixtures were kept under agitation and impregnation for $12 \mathrm{~h}$. The subsequent solutions were dried at $100{ }^{\circ} \mathrm{C}$ and the products in the form of white powder were obtained. The three samples were designated as 50PTA@FMC, 75PTA@FMC, and 100PTA@FMC.

\subsection{Characterization}

Information on the characterization tests can be found in the ESI (Section 1†), including the results of nitrogen adsorptiondesorption, powder X-ray diffraction (PXRD), scanning electron microscopy (SEM), and Fourier transform infrared spectroscopy (FTIR) studies.

\subsection{Batch equilibrium}

2.4.1. Adsorption isotherms. The adsorption isotherms determine the equilibrium adsorption amount of adsorbates onto adsorbents at a certain temperature. Herein, we used rubidium ions as the adsorbate and the PTA@FMC materials as the adsorbent. The experiments were carried out according to the following procedures. In detail, in each Erlenmeyer flask, $0.02 \mathrm{~g}$ of the PTA@FMC material was taken and then $50 \mathrm{~mL}$ of rubidium chloride solution of different initial concentrations ranging from $10 \mathrm{mg} \mathrm{L}^{-1}$ to $100 \mathrm{mg} \mathrm{L}^{-1}$ was added. After that, the mixture was shaken in a thermostatic shaker at $30{ }^{\circ} \mathrm{C}$ with a rotating speed of $150 \mathrm{rpm}$ for $12 \mathrm{~h}$; the adsorption process takes place in this condition. After the adsorption, the solution mixture was kept undisturbed for several minutes till the clear solution in the upper layer was collected. The concentration of the remaining rubidium ions was tested via atomic adsorption spectroscopy (AAS). It was found that after PTA doping, the $\mathrm{Rb}^{+}$ uptake capacity of PTA@FMC significantly increased in comparison with that of FMC, which could probably be explained by the Lewis acid-base interaction mechanism. $\mathrm{Rb}^{+}$ shows a Lewis acid performance, and PTA has a lone pair of electrons, which exhibits a Lewis base feature. Thus, the strong chemical bonding between PTA and $\mathrm{Rb}^{+}$could lead to a specific adsorption and increase in the adsorption capacity. When the doping level of PTA was further increased, the amount of PTA sites consequently increased, which aroused a better adsorption capacity in 75PTA@FMC than in 50PTA@FMC. However, further PTA doping might block the pores and lead to an increase in the diffusion resistance during the mass transfer reactions, which actually can decline the amount of accessible active PTA sites. Thus, the sorbent with higher PTA doping (100PTA@FMC) shows a lower $\mathrm{Rb}^{+}$uptake capacity than that with comparatively lower PTA loading (75PTA@FMC).

2.4.2. Adsorption kinetics. The adsorption kinetics of rubidium ions onto the FMC was also studied in detail. The experiments were carried out as follows. Specifically, in each 
Erlenmeyer flask with $50 \mathrm{~mL}$ of $100 \mathrm{mg} \mathrm{L}^{-1}$ rubidium ion solution, $0.02 \mathrm{~g}$ of PTA@FMC materials was added. After that, the Erlenmeyer flasks were put in a thermostatic shaker at a temperature of $25{ }^{\circ} \mathrm{C}$ and with the rotating speed of $150 \mathrm{rpm}$. The adsorption takes place in this process. Similarly, after the adsorption, the solution mixture was left undisturbed for several minutes till the clear solution in the upper layer was collected. The concentration of the remaining rubidium ions was tested via atomic adsorption spectroscopy (AAS).

\subsection{Influence of interfering ions}

2.5.1. The influence from $\mathrm{Na}^{+}$and $\mathbf{K}^{+}$. Metal ions except for rubidium ions are thought to interfere with the adsorption process of rubidium ions onto the adsorbents. In this part, we majorly tested the interference from $\mathrm{Na}^{+}$and $\mathrm{K}^{+}$. The experiments were carried out as follows. A series of adsorbate solutions were prepared and placed in $50 \mathrm{~mL}$ Erlenmeyer flasks: $100 \mathrm{mg} \mathrm{L}^{-1} \mathrm{Rb}^{+}$and $10 \mathrm{mg} \mathrm{L^{-1 }} \mathrm{M}^{+}, 100 \mathrm{mg} \mathrm{L}{ }^{-1} \mathrm{Rb}^{+}$and $30 \mathrm{mg} \mathrm{L}{ }^{-1} \mathrm{M}^{+}, 100 \mathrm{mg} \mathrm{L}^{-1} \mathrm{Rb}^{+}$and $50 \mathrm{mg} \mathrm{L}^{-1} \mathrm{M}^{+}, 100 \mathrm{mg} \mathrm{L}^{-1}$ $\mathrm{Rb}^{+}$and $70 \mathrm{mg} \mathrm{L}{ }^{-1} \mathrm{M}^{+}, 100 \mathrm{mg} \mathrm{L}{ }^{-1} \mathrm{Rb}^{+}$and $100 \mathrm{mg} \mathrm{L}^{-1} \mathrm{M}^{+}$,

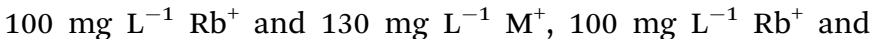
$150 \mathrm{mg} \mathrm{L}^{-1} \mathrm{M}^{+}, 100 \mathrm{mg} \mathrm{L}^{-1} \mathrm{Rb}^{+}$and $170 \mathrm{mg} \mathrm{L}^{-1} \mathrm{M}^{+}, 100 \mathrm{mg} \mathrm{L}^{-1}$ $\mathrm{Rb}^{+}$and $200 \mathrm{mg} \mathrm{\textrm {L } ^ { - 1 }} \mathrm{M}^{+}$. In each Erlenmeyer flask, $0.02 \mathrm{~g}$ of the PTA@FMC material was then added. The solution mixture was put in a thermo-static shaker under the conditions of $30{ }^{\circ} \mathrm{C}$ and $150 \mathrm{rpm}$. The adsorption process proceeded for $4 \mathrm{~h}$. After that, the clear solution in the upper layer was collected and the concentration of the remaining rubidium ions was tested using AAS. Consequently, the corresponding adsorption amount of rubidium ions was calculated.

2.5.2. The amount of interfering ions. In this part, we delved into the influence of the number of interfering ions on the $\mathrm{Rb}^{+}$adsorption amount. We measured the change in the adsorption capacity of $\mathrm{Rb}^{+}$onto FMC and PTA@FMC when one, two or three types of interfering ions were added. The experimental procedures were as follows. Circumstance one: when adding one type of interfering ion into the adsorption system. The ion can be $\mathrm{Na}^{+}$or $\mathrm{K}^{+}$or $\mathrm{Cs}^{+}$. A $50 \mathrm{~mL}$ solution containing $50 \mathrm{mg} \mathrm{L}{ }^{-1}$ of $\mathrm{M}^{+}\left(\mathrm{Na}^{+}, \mathrm{K}^{+}\right.$, or $\left.\mathrm{Cs}^{+}\right)$and $100 \mathrm{mg} \mathrm{L}^{-1}$ of $\mathrm{Rb}^{+}$was prepared, and the adsorption amount of $\mathrm{Rb}^{+}$onto the FMC and PTA@FMC was studied. Circumstance two: when adding two types of interfering ions into the adsorption system. The ions can be $\mathrm{Na}^{+}, \mathrm{K}^{+}$or $\mathrm{Na}^{+}, \mathrm{Cs}^{+}$or $\mathrm{K}^{+}, \mathrm{Cs}^{+}$. A $50 \mathrm{~mL}$ solution containing $50 \mathrm{mg} \mathrm{L}^{-1}$ of both interfering ions and $100 \mathrm{mg} \mathrm{L}^{-1}$ of $\mathrm{Rb}^{+}$was prepared, and the adsorption amount of $\mathrm{Rb}^{+}$onto the FMC and PTA@FMC was studied. Circumstance 3: when adding three types of interfering ions into the adsorption system. The ion combination was $\mathrm{Na}^{+}$and $\mathrm{K}^{+}$and $\mathrm{Cs}^{+}$. A $50 \mathrm{~mL}$ solution containing $50 \mathrm{mg} \mathrm{L}^{-1}$ of the three types of interfering ions and $100 \mathrm{mg} \mathrm{L}^{-1}$ of $\mathrm{Rb}^{+}$was prepared, and the adsorption amount of $\mathrm{Rb}^{+}$onto the FMC and PTA@FMC was studied. The adsorption process was carried out by the method mentioned in the section on adsorption isotherms.

2.5.3. Calculation of the $\mathbf{R b}^{+}$uptake capacities. All the $\mathrm{Rb}^{+}$ uptake capacities $\left(\mathrm{mg} \mathrm{g}^{-1}\right)$ were calculated from the difference between the final and initial concentrations of the adsorbate using the following equation:

$$
q_{\mathrm{e}}=\frac{\left(C_{\mathrm{o}}-C_{\mathrm{e}}\right) V}{M}
$$

where $C_{\mathrm{o}}$ and $C_{\mathrm{e}}\left(\mathrm{mg} \mathrm{\textrm {L } ^ { - 1 }}\right)$ are the initial and equilibrium concentrations of the metal ion solution, respectively; $V(\mathrm{~L})$ is the volume of the solution, and $M(\mathrm{~g})$ is the mass of the adsorbent materials used.

\section{Results and conclusion}

\subsection{Characterization}

3.1.1. $\mathbf{N}_{2}$ adsorption/desorption. Fig. 1 displays the $\mathbf{N}_{2}$ adsorption/desorption curve. From this figure and Table S.I.1, $\dagger$ we can see that each of the three samples along with the adsorbent carrier FMC has an obvious $\mathrm{H}_{1}$-type hysteresis loop, ${ }^{25,26}$ and the adsorption branches are parallel, indicating that the FMC and the PTA@FMC materials are typical mesoporous materials. Meanwhile, the introduction of PTA onto the FMC decreased the specific area of the carrier; as the amount of PTA loading increased, the decrease in the specific area aggravated. Fig. S.I.1† displays the pore distribution diagram. From this figure, we can see that the pore distribution of all the PTA@FMC materials along with the FMC carrier is very narrow with the majority of the pores having a diameter of $4 \mathrm{~nm}$. The distribution curves of PTA@FMC are similar to that of FMC. At the same time, after the loading of PTA, the pore volume and pore size decreased rapidly, which indicates that the loading of PTA clogged a part of the channels in the FMC.

3.1.2. Scanning electron microscopy (SEM) characterization. The SEM analyses were carried out to obtain the morphology of the surface of the tested materials. For comparison, the SEM images of the FMC and PTA@FMC are separately presented in Fig. S.I.2. $\dagger$ In detail, images (a) and (b) represent the surface characteristics of the FMC and images (c) and (d) represent those of the PTA@FMC. From the images, we

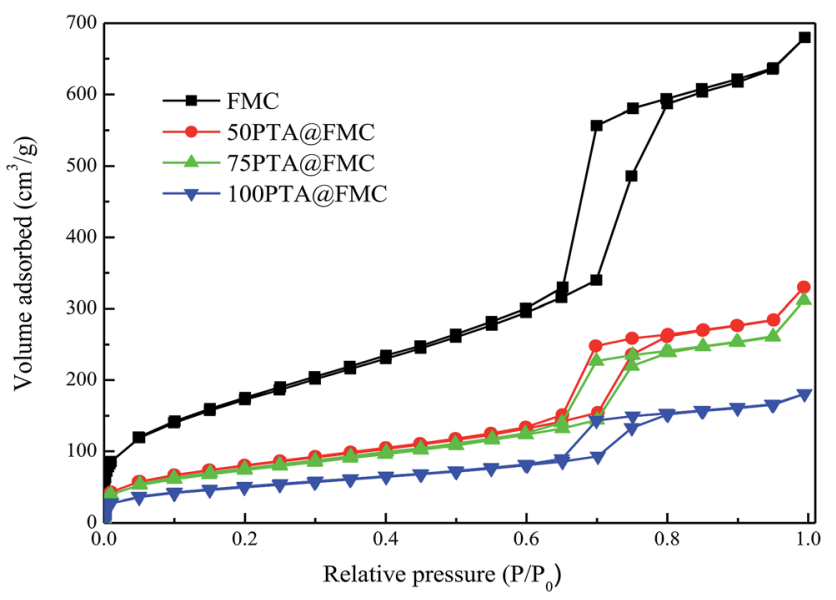

Fig. $1 \mathrm{~N}_{2}$ adsorption/desorption isotherms of the PTA@FMC materials. 
can tell that the surface characteristics of the FMC have not been disturbed visibly by the loading of PTA.

3.1.3. Fourier transform infrared (FT-IR) spectroscopy. FTIR spectroscopy was employed to analyze the molecular structure of materials. The FT-IR spectra of FMC and PTA@FMC are shown in Fig. S.I.3. $\dagger$ The corresponding peaks of the PTA@FMC materials at $983 \mathrm{~cm}^{-1}$ and $892 \mathrm{~cm}^{-1}$ demonstrate that PTA has been loaded onto the FMC, indicating that PTA@FMC has been successfully prepared. Besides, the spectrum of FMC has three distinctive characteristic peaks at $3423 \mathrm{~cm}^{-1}, 1082 \mathrm{~cm}^{-1}$ and $464 \mathrm{~cm}^{-1}$, representing the vibrational peaks of the $\mathrm{Si}-\mathrm{OH}$ bond, the telescopic vibration of the $\mathrm{Si}-\mathrm{O}$ bond, and the telescopic vibrational peak of the $\mathrm{O}-\mathrm{Si}-\mathrm{O}$ bond, respectively. ${ }^{3,14,15}$ The characteristic peaks of FMC also appear in the spectrum of PTA@FMC materials, indicating that PTA@FMC has a similar structure as that of FMC materials. In addition, the infrared spectrum of PTA shows the characteristic peaks at $983 \mathrm{~cm}^{-1}$ and $892 \mathrm{~cm}^{-1}$, which can be attributed to the telescopic vibration of the $\mathrm{W}=\mathrm{O}$ bond and the telescopic vibration of the $\mathrm{W}-\mathrm{O}-\mathrm{W}$ bond, respectively.

3.1.4. X-ray diffraction (XRD). Information on the composition of the materials and the structure or morphology of the atoms or molecules in the materials was obtained through XRD characterization. The XRD patterns of FMC and PTA@FMC are presented in Fig. S.I.4. $\dagger$ From the figure, we can conclude that the FMC has three evident characteristic peaks located at (100), (110), and (200). As the loading amount of PTA increased, the characteristic diffraction intensity of the PTA@FMC samples at (100), (110), and (200) decreased obviously.

\subsection{Batch adsorption}

3.2.1. Adsorption isotherms. The results of adsorption isotherms are plotted in Fig. 2, from which we found that, for all the samples, the adsorption amount of rubidium ion increases as the initial concentration of rubidium ion solution increases. Besides, from the figure, it can be obviously found that the FMC has a better adsorption capacity towards rubidium ions after the

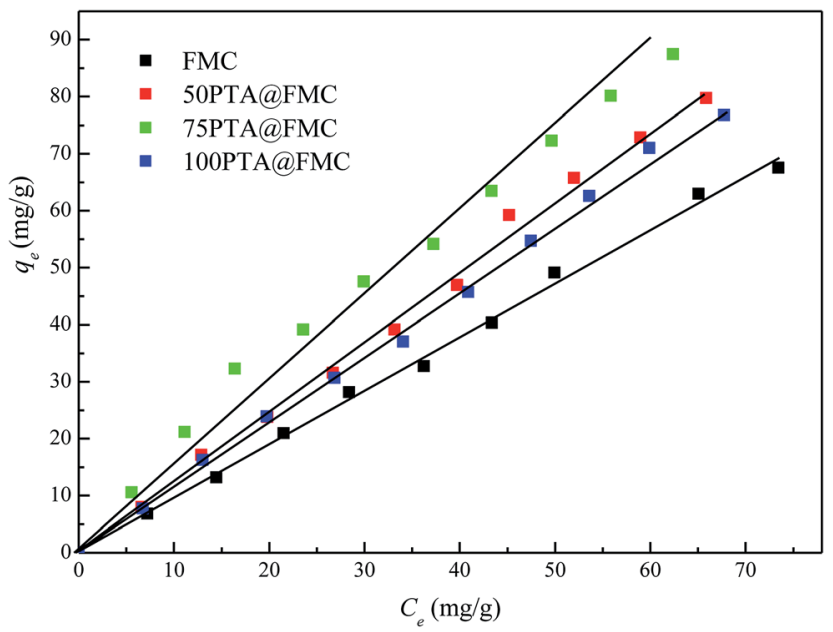

Fig. 2 Adsorption isotherms of the PTA@FMC materials. loading of PTA, which primarily results from the selective adsorption entailed by the existence of PTA. The adsorption capacity of PTA of the PTA@FMC materials ranks in the following sequence: 75PTA@FMC > 50PTA@FMC > 100PTA@FMC > FMC. The maximum adsorption capacity of 75PTA@FMC for $\mathrm{Rb}^{+}$was $86.50 \mathrm{mg} \mathrm{g}^{-1}$ under our experimental conditions, which is higher than that previously reported for a surface ion-imprinting material and a composite adsorbent (Table S.I. $2 \dagger$ ). ${ }^{3,23,24}$ The adsorption isotherms (Table S.I. $3 \dagger$ ) were fitted into four typical adsorption models (Langmuir model, Freundlich model, Temkin model and D-R model). ${ }^{25-31}$ The fitting results (Table S.I.4†) show that the adsorption process of rubidium ions onto the PTA@FMC materials is well-suited to the Freundlich model with a $R^{2}$ value larger than 0.9925 , while the $R^{2}$ values of other models are less than 0.9350 . In addition, the $n$ value of the Freundlich model evaluates the adsorption intensity and the homogeneity of the adsorbents. According to the fitting results displayed in the table, the value of $1 / n$ less than 1 indicates the ease of the adsorption process while that approaching 1 indicates the uniformity of the adsorbent surface.

3.2.2. Adsorption kinetics. The results of the adsorption kinetics were plotted and is shown in Fig. 3. From this figure, we can discover that the adsorption process of rubidium ions onto the FMC proceeds rapidly, and nearly after 15 minutes the adsorption reaches equilibrium. Comparing the four materials, their rubidium ion adsorption capacity ranks were in the order of 75PTA@FMC > 50PTA@FMC > 100PTA@FMC > FMC with the equilibrium adsorption amount of rubidium ions of 85, 78, 76 and $65 \mathrm{mg} \mathrm{g}^{-1}$, respectively. Consistently, the results of the adsorption kinetics (Table S.I.5 $\dagger$ ) were fitted into three typical models (pseudo-first-order, pseudo-second-order and intradiffusion). ${ }^{32,33}$ The fitting results are recorded in Table S.I.6, $\dagger$ from which we can conclude that the adsorption kinetics of this process fits well to the pseudo-second-order adsorption kinetics model with a $R^{2}$ value larger than 0.9995 . Furthermore, based on the fitting results of the particle diffusion model of $q_{\mathrm{t}}$ versus

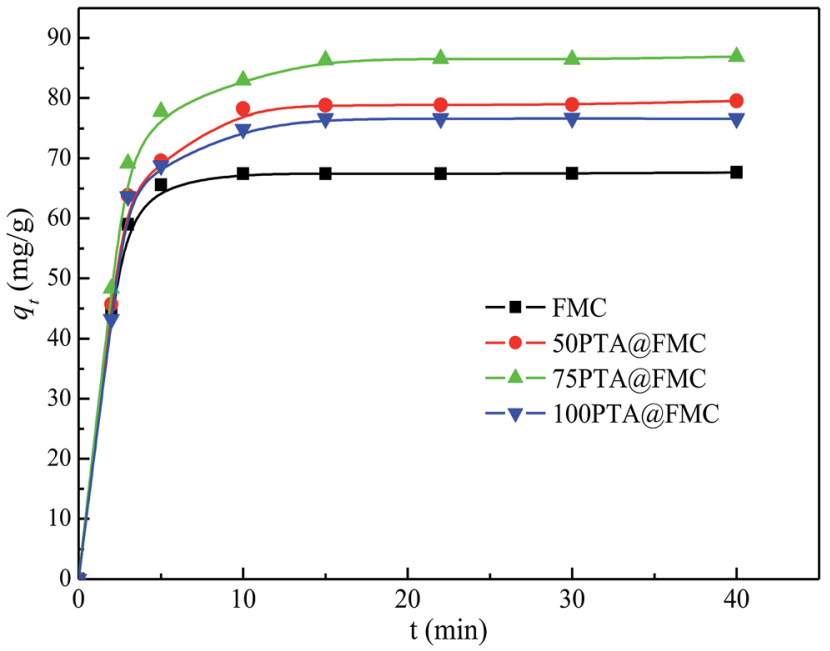

Fig. 3 Adsorption kinetics of the PTA@FMC materials. 
$t^{1 / 2}$, which is shown in Fig. 3, it can be seen that in the whole time period, there are two straight lines in the graph. The first stage can be attributed to the direct diffusion of rubidium ions into the mesopores of the sorbents, and the second stage of the linear part can be attributed to the diffusion of rubidium ions into the micropores. The results show that the adsorption of $\mathrm{Rb}^{+}$on the FMC and PTA@FMC involves multiple steps, and particle diffusion is not the only rate-limiting step. Such a finding is similar to that made in previous works on adsorption. ${ }^{34,35}$

\subsection{The interference of interfering ions}

3.3.1. The interference of $\mathrm{Na}^{+}$and $\mathbf{K}^{+}$. The experimental results are plotted in Fig. 4. According to the displayed relationship between the adsorption amount of rubidium ions and the concentration of the added interfering ions $\left(\mathrm{Na}^{+}\right.$or $\left.\mathrm{K}^{+}\right)$, we can see that in the presence of an interfering ion, the adsorption amount of rubidium ions onto the PTA@FMC has been negatively affected. The adsorption amount of rubidium ions
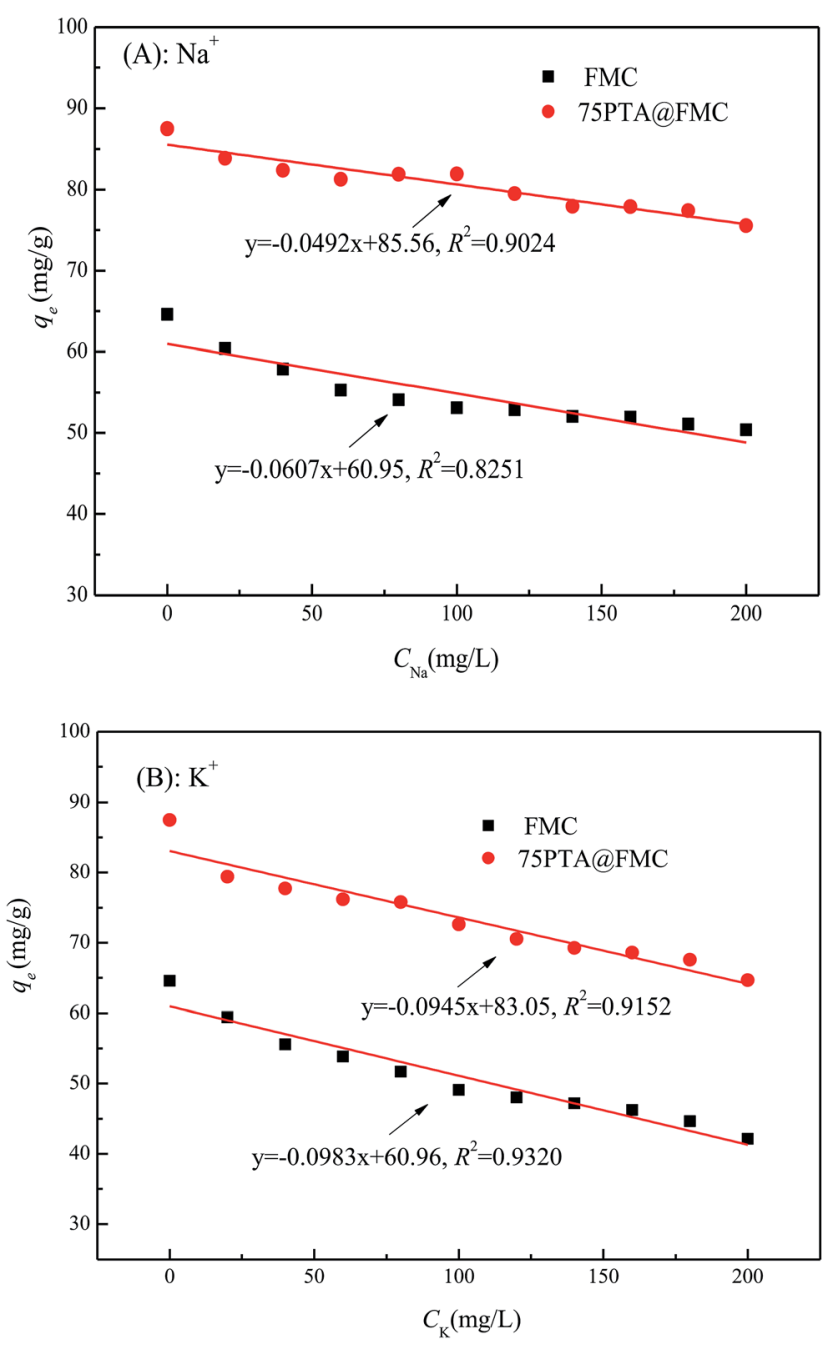

Fig. 4 Relationship between the adsorption amount of $\mathrm{Rb}^{+}$onto the FMC or PTA $A F M C$ and the added amount of $\mathrm{Na}^{+}$and $\mathrm{K}^{+}$. (A): $\mathrm{Na}^{+} ;(\mathrm{B})$ : $\mathrm{K}^{+}$. decreases as the added amount of interfering ions increases, and this tendency appears to be approximately linear, which illustrates that the presence of $\mathrm{Na}^{+}$or $\mathrm{K}^{+}$has a competitive adsorption effect on the adsorption of $\mathrm{Rb}^{+}$. Furthermore, we have calculated the reduction rate of the adsorption amount of $\mathrm{Rb}^{+}$using the following equation:

$$
X(\%)=\frac{\left(q_{\mathrm{e}}-q\right)}{q_{\mathrm{e}}} \times 100 \%
$$

where $X$ represents the percent of the reduction rate of the adsorption amount of $\mathrm{Rb}^{+}, q_{\mathrm{e}}$ is the adsorption amount of $\mathrm{Rb}^{+}$ without the interference of interfering ions, and $q$ is the adsorption amount of $\mathrm{Rb}^{+}$with the interference of the interfering ions.

The relationship between the reduction rate of the adsorption amount of $\mathrm{Rb}^{+}$onto the adsorbents (FMC and PTA@FMC materials) and the added concentration of the interfering ions $\left(\mathrm{Na}^{+}\right.$and $\left.\mathrm{K}^{+}\right)$is plotted in Fig. 5. From Fig. 5, we can mainly draw three conclusions. First of all, the reduction rate of the adsorption amount of $\mathrm{Rb}^{+}$decreases along with the increase in the added amount of interfering ions, which is consistent with the results mentioned above. In addition, the interference effect of $\mathrm{K}^{+}$on the adsorption of $\mathrm{Rb}^{+}$onto both the FMC and PTA@FMC is larger than that of $\mathrm{Na}^{+}$, as evidenced by the higher reduction rate of the adsorption amount of $\mathrm{Rb}^{+}$. Finally, regardless that the interference is by $\mathrm{Na}^{+}$or $\mathrm{K}^{+}$, the reduction in the percentage of adsorption of $\mathrm{Rb}^{+}$onto the $\mathrm{FMC}$ is larger than that onto the corresponding PTA@FMC, indicating that the loading of PTA can abate the influence of the interfering ions on the adsorption of $\mathrm{Rb}^{+}$.

3.3.2. The amount of interfering ions. The experimental results that present the reduction in $\mathrm{Rb}^{+}$adsorption rates versus the amount of interfering ions are shown in Fig. S.I.5. $\dagger$ As can be seen from Fig. S.I.5, $\dagger$ with the increase in the number of types of interfering ions from one to three, the adsorption capacity of $\mathrm{Rb}^{+}$onto the FMC and PTA@FMC gradually decreases; the adsorption amount of $\mathrm{Rb}^{+}$onto the FMC

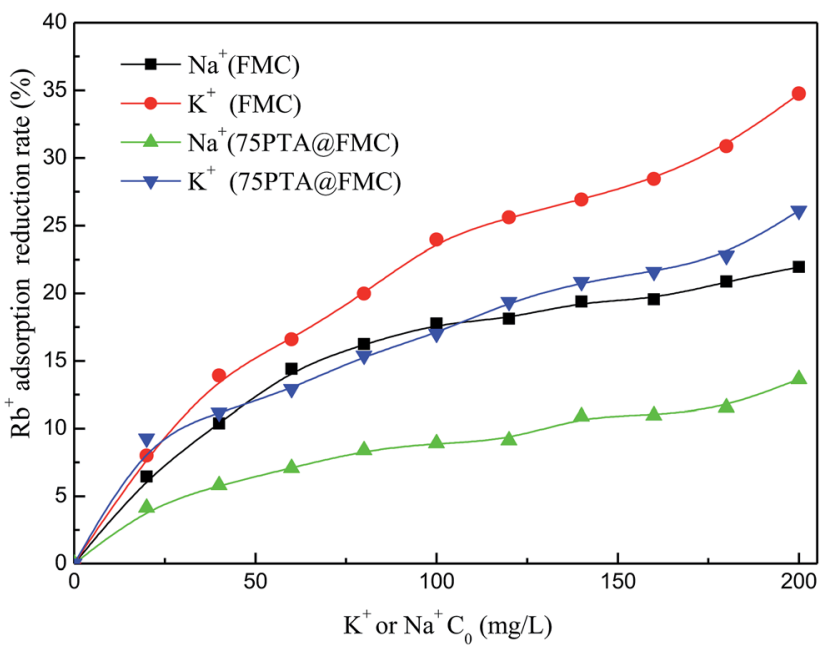

Fig. 5 The reduction rate of the adsorption amount of $\mathrm{Rb}^{+}$versus the added amount of $\mathrm{Na}^{+}$and $\mathrm{K}^{+}$. 
decreases from the original $65 \mathrm{mg} \mathrm{g}^{-1}$ to $43 \mathrm{mg} \mathrm{g}^{-1}$, and the adsorption amount of $\mathrm{Rb}^{+}$onto the PTA@FMC decreases from the original $87 \mathrm{mg} \mathrm{g}^{-1}$ to $63 \mathrm{mg} \mathrm{g}^{-1}$. It can be seen that the degree of interference of $\mathrm{Na}^{+}, \mathrm{Cs}^{+}$and $\mathrm{K}^{+}$on $\mathrm{Rb}^{+}$adsorption is varying; irrespective of the adsorption of $\mathrm{Rb}^{+}$onto the FMC or PTA@FMC materials, the degree of interference is in the order of $\mathrm{Cs}^{+}>\mathrm{K}^{+}>\mathrm{Na}^{+}$. Furthermore, we similarly calculated and plotted the relationship between the reduction rates of the adsorption amount of $\mathrm{Rb}^{+}$and the number of interfering ions. The results are shown in Fig. S.I.6. $\dagger$ It can be seen from Fig. S.I.6† that with the increase in the number of interfering ions, the reduction rate of the adsorption capacity of the two materials increases, indicating that the interfering ions have an adverse effect on the adsorption of $\mathrm{Rb}^{+}$. The possible explanation is that $\mathrm{Na}, \mathrm{K}, \mathrm{Rb}$ and $\mathrm{Cs}$ are all alkali metals belonging to the first main group of the periodic table, implying that there might be a certain amount of competitive adsorption between them.

The adsorption of $\mathrm{Rb}^{+}$ions is achieved depending on various factors like the physical and/or chemical properties of the adsorbents and the mass transfer process. ${ }^{35-42}$ For example, the Lewis acid-base interaction might be the main factor affecting the $\mathrm{K}^{+}, \mathrm{Na}^{+}$and $\mathrm{Rb}^{+}$adsorption process in this study. According to Pearson's hard and soft acid-base concept, bases can be classified into two categories. One type of bases is polarizable, and the other type is non-polarizable. These two groups are denoted as "soft" and "hard" bases, respectively. Similarly, acids can be classified based on their preferential interaction with hard or soft bases. That is, acids that form strong interactions with hard and soft bases are called hard and soft acids, respectively. According to this concept, for the same family elements Na, K, and $\mathrm{Rb}$, with the increase in the atomic number, the electron layer increases, and the radius of the atom increases. The attraction of the nucleus to the outermost electrons decreases, and the electron losing ability of the atom increases. $\mathrm{Rb}^{+}$exhibiting the characteristic of a Lewis acid is relatively soft than $\mathrm{Na}^{+}$ and $\mathrm{K}^{+}$. Thus, the relatively soft $\mathrm{Rb}^{+}$might be strongly attracted to soft Lewis bases, such as the phosphomolybdic ion. Thus, the uptake of $\mathrm{Rb}^{+}$is higher than those of $\mathrm{Na}^{+}$and $\mathrm{K}^{+}$.

3.3.3. Recyclability studies. The recyclability of the PTA/ FMC and the desorption efficiency of $\mathrm{Rb}^{+}$are important in pollution control and environmental protection. Based on the solvent elution procedures in the literatures, ${ }^{3,23}$ the regeneration of the adsorbent was achieved by using $\mathrm{NH}_{4} \mathrm{NO}_{3}\left(5 \mathrm{~mol} \mathrm{~L}^{-1}\right)$ as an eluent at $25{ }^{\circ} \mathrm{C}$. The effects of the number of times of regeneration are shown in Fig. S.I.7. $\dagger$ In comparison with fresh 75PTA@FMC, the adsorption capacity decreased by less than 3\% in the second cycle and then it remained almost at the same level. By the fifth regeneration, the adsorption capacity decreased by $5 \%$, but still remained at a high value. As a whole, the as-prepared adsorbent, i.e., 75PTA@FMC, can be easily regenerated after the adsorption process and recycled five times at least.

\section{Conclusion}

In this study, we have eliminated the limitation of the diffusion of microporous materials, using the ordered mesoporous material FMC to prepare a novel heteropoly acid-functionalized sorbent (PTA@FMC). The experimental characterization manifests that this composite material shows no significant difference in the structural characteristics from those of the FMC, implying that the introduction of PTA does not disturb the structure of FMC. In addition, according to the batch equilibrium experiments of rubidium ion adsorption by the PTA@FMC materials, we demonstrated that these materials have a satisfactory $\mathrm{Rb}^{+}$adsorption capacity, among which 75PTA@FMC is the most distinctive. The influence of interfering ions on the adsorption of $\mathrm{Rb}^{+}$has also been probed into, and several pieces of worthy information have been obtained. Above all, it has been confirmed that $\mathrm{Cs}^{+}, \mathrm{K}^{+}$, and $\mathrm{Na}^{+}$have a competitive adsorption effect on the adsorption of $\mathrm{Rb}^{+}$, and $\mathrm{Cs}^{+}$is the most competitive one. Furthermore, the amount of interfering ions also has a significant effect on the adsorption of $\mathrm{Rb}^{+}$. We tested the effect on the adsorption of rubidium ion by separately adding one, two, and three types of interfering ions $\left(\mathrm{Na}^{+}, \mathrm{K}^{+}\right.$, $\left.\mathrm{Cs}^{+}\right)$. The results showed that more the added amount of the different types of interfering ions, the more severe is the degree by which the adsorption of $\mathrm{Rb}^{+}$is weakened. In a word, due to its relatively facile preparation process, low cost and good adsorption capacity, PTA@FMC is a promising adsorption material for $\mathrm{Rb}^{+}$.

\section{Conflicts of interest}

There are no conflicts to declare.

\section{Acknowledgements}

We thank the Zhejiang Provincial Natural Science Foundation of China under Grant No. LY19B060014.

\section{References}

1 N. Moazezi and M. A. Moosavian, J. Environ. Chem. Eng., 2016, 4, 2440-2449.

2 P. Xing, C. Wang, B. Z. Ma, W. J. Zhang and Y. Q. Chen, Chem. Eng., 2018, 6, 4922-4930.

3 W. Dai, Y. Y. Fang, L. Yu, G. H. Zhao and X. Y. Yan, J. Taiwan Inst. Chem. Eng., 2018, 84, 222-228.

4 M. R. Awual, M. Khraisheh, N. H. Alharthi, M. Luqman, A. Islam, M. R. Karim, M. M. Rahman and M. A. Khaleque, Chem. Eng. J., 2018, 343, 118-127.

5 K. Abbas, H. Znad and M. R. Awuala, Chem. Eng. J., 2018, 334, 432-443.

6 A. Shahata, H. M. A. Hassana, H. M. E. Azzazy, E. A. ElSharkawy, H. M. Abdou and M. R. Awual, Chem. Eng. J., 2018, 332, 377-386.

7 M. R. Awual, N. H. Alharthi, M. M. Hasan, M. R. Karim, A. Islam, H. Znad, M. A. Hossain, M. E. Halim, M. M. Rahman and M. A. Khaleque, Chem. Eng. J., 2017, 324, 130-139.

8 M. R. Awual, N. H. Alharthi, Y. Okamoto, M. R. Karim, M. E. Halim, M. M. Hasan, M. M. Rahman, M. M. Islam, 
M. A. Khaleque and M. C. Sheikh, Chem. Eng. J., 2017, 320, 427-435.

9 M. R. Awual, Chem. Eng. J., 2017, 307, 85-94.

10 M. R. Awual, Chem. Eng. J., 2017, 307, 456-465.

11 M. R. Awual, Chem. Eng. J., 2016, 303, 539-546.

12 M. R. Awual, Chem. Eng. J., 2016, 300, 264-272.

13 M. R. Awual, Y. Miyazaki, T. Taguchi, H. Shiwaku and T. Yaita, Chem. Eng. J., 2016, 291, 128-137.

14 M. R. Awual, Chem. Eng. J., 2016, 289, 65-73.

15 M. R. Awual, M. M. Hasan, M. A. Khaleque and M. C. Sheikh, Chem. Eng. J., 2016, 288, 368-376.

16 M. R. Awual, T. Yaita, H. Shiwaku and S. Suzuki, Chem. Eng. J., 2015, 276, 1-10.

17 M. R. Awual, T. Yaita, S. Suzuki and H. Shiwaku, J. Hazard. Mater., 2015, 291, 111-119.

18 M. R. Awual, Chem. Eng. J., 2015, 266, 368-375.

19 M. R. Awual, M. M. Hasan and M. A. Khaleque, Sens. Actuators, B, 2015, 209, 194-202.

20 M. R. Awual and M. M. Hasan, Sens. Actuators, B, 2015, 206, 692-700.

21 M. R. Awual, M. M. Hasan and H. Znad, Chem. Eng. J., 2015, 259, 611-619.

22 H. Aghayan, A. R. Khanchi, T. Yousefi and H. Ghasemi, J. Nucl. Mater., 2017, 496, 207-214.

23 Y. Fang, G. Zhao, W. Dai, L. Ma and N. Ma, Microporous Mesoporous Mater., 2017, 251, 51-57.

24 Y. Fang, W. Dai, L. Chen and N. Ma, Mater. Lett., 2016, 174, 246-248.

25 G. Naidu, T. Nur, P. Loganathan, J. Kandasamy and S. Vigneswaran, Sep. Purif. Technol., 2016, 163, 238-246.

26 M. R. Awual, M. M. Hasan, T. Ihara and T. Yaita, Microporous Mesoporous Mater., 2014, 197, 331-338.
27 M. R. Awual and M. M. Hasan, Microporous Mesoporous Mater., 2014, 196, 261-269.

28 M. R. Awual, T. Yaita, T. Taguchi, H. Shiwaku, S. Suzuki and Y. Okamoto, J. Hazard. Mater., 2014, 278, 227-235.

29 M. R. Awual, S. Suzuki, T. Taguchi, H. Shiwaku, Y. Okamoto and T. Yaita, Chem. Eng. J., 2014, 242, 127-135.

30 M. R. Awual, I. M. M. Rahman, T. Yaita, M. A. Khaleque and M. Ferdows, Chem. Eng. J., 2014, 236, 100-109.

31 M. R. Awual, T. Yaita and H. Shiwaku, Chem. Eng. J., 2013, 228, 327-335.

32 G. Naidu, S. Jeong, Y. K. Choi, M. H. Song, U. Oyunchuluun and S. Vigneswaran, J. Cleaner Prod., 2018, 174, 1079-1088.

33 X. J. Huang, L. Y. An, X. Y. Zhao and X. Q. Chen, Adv. Mater. Res., 2013, 652, 2524-2528.

34 D. L. Guerra, A. C. Batista, R. R. Viana and A. i. Claudio, Desalination, 2011, 275, 107-117.

35 N. Gayathri, L. Paripurnanda, J. Sanghyung, H. J. M. Abu, P. T. Vu Hien, K. Jaya and V. Saravanamuthu, Chem. Eng. J., 2016, 306, 31-42.

36 M. R. Awual, M. Ismael, T. Yaita, S. A. El-Safty, H. Shiwaku, Y. Okamoto and S. Suzuki, Chem. Eng. J., 2013, 222, 67-76.

37 M. R. Awual, T. Yaita, S. A. El-Safty, H. Shiwaku, Y. Okamoto, S. Suzuki and Y. Okamoto, Chem. Eng. J., 2013, 221, 322-330. 38 A. Shahat, M. R. Awual and M. Naushad, Chem. Eng. J., 2015, 271, 155-163.

39 M. R. Awual, G. E. Eldesoky, T. Yaita, M. Naushad, H. Shiwaku, Z. A. AlOthman and S. Suzuki, Chem. Eng. J., 2015, 279, 639-647.

40 M. R. Awual, J. Ind. Eng. Chem., 2014, 20, 3493-3501.

41 Y. Onodera, T. Iwasaki, H. Hayashi and K. Torii, Nippon Kogyo Kaishi, 1988, 104, 277-282.

42 R. Gong, J. J. Ye, W. Dai, X. Y. Yan, J. Hu, X. Hu, S. Li and H. Huang, Ind. Eng. Chem. Res., 2013, 52, 14297-14303. 